DOI 10.38129/ Ann.Yur.Ist.2020.4.1.61

УДК 796.011.1: 796.035(364.013:349.3)

\title{
СОВЕРШЕНСТВОВАНИЕ ПРАВОВОГО РЕГУЛИРОВАНИЯ АДАПТИВНОГО СПОРТИВНОГО ДВИЖЕНИЯ В РЕСПУБЛИКЕ БЕЛАРУСЬ
}

\author{
ЮЛИЯ ГАВРИЛЬЧЕНКО (Минск, Беларусь) *
}

Всеобщей тенденцией последних десятилетий является рост инвалидности. По данным Всемирной организации здравоохранения инвалиды составляют около 15 \% населения Земли, при этом в 70-х гг. XXв. их количество оставалось на уровне $10 \% 1$.

Улучшение физического и психического состояния, а также общая социализация таких людей - один из важнейших аспектов решения проблемы дискриминации лиц с ограниченными возможностями.

Предполагается, что реабилитация должна включать, во-первых, медицинскую реабилитацию, состоящую из восстановительной терапии, реконструктивной хирургии и др.; во-вторых, профессиональную реабилитацию, которая заключается в помощи лицу с ограниченными возможностями профессионально переориентироваться (при утрате или значительном ограничении трудовых навыков), получить профессиональное образование и трудоустроиться, адаптируясь в новой трудовой среде; втретьих, собственно социальную реабилитацию (как полноценного гражданина общества, члена семьи, равноправного человека со своим социально-бытовым, человеческим окружением) ${ }^{2}$. Применительно к лицам с особенностями в развитии, имеющимися с раннего возраста, используется термин абилитация как лечебные, социальные и другие мероприятия, направленные на адаптацию их к существующим условиям жизни.

Нельзя согласиться с обоснованностью идеи о том, что люди с ограниченными возможностями «при соответствующей подготовке, рассматриваются как имеющие возможность обеспечить свое существование

${ }^{1}$ Сунагатова Л. В., Марченкова У. А. Влияние адаптивного спорта на социальную адаптацию инвалидов / / Молодой ученый. - 2012. - №12. - С. 603.

${ }^{2}$ Шокина И. Н. Адаптивный спорт как условие сохранения и укрепления здоровья инвалидов / / Вестник Поволжского института управления. - 2008. - № 15. - С. 81. 
сами, т. е. не быть бременем» . Полагаем, в современном обществе человек с ограниченными возможностями, независимо от своей дееспособности и активности, не должен рассматриваться в контексте «бремя - не бремя», являясь полноправным членом социума, способным к разносторонней и полной реализации своего потенциала. При этом адаптивное движение, освещение в СМИ соревнований, достижений адаптивных спортсменов, учебно-тренировочного процесса способствуют гуманизации всего социума, духовно-нравственному и физическому воспитанию подрастающего поколения.

Научные исследования, зарубежная и отечественная практика убедительно доказывают, что занятия физической культурой и спортом для лиц с ограниченными возможностями опорно-двигательного аппарата, зрения, слуха, интеллекта и других функций не менее важны, чем для обычных людей. Более того, социальная, психическая и физическая реабилитация и абилитация таких лиц невозможны без физической активности и социальной коммуникации, которые обеспечиваются тренировками и участием в физкультурно-спортивных мероприятиях. Таким образом, всесторонняя поддержка адаптивного движения является важной составляющей государственной социально-экономической политики любого цивилизованного государства.

Зарождение основ адаптивных физкультуры и спорта произошло в глубокой древности. Однако важные теоретические обоснования данного направления в научной литературе обычно датируются XVIII-XIX вв. ${ }^{4}$

Первые Всемирные игры глухих прошли в Париже 10-17 августа 1924 года. В них участвовали спортсмены - представители официальных национальных федераций Бельгии, Великобритании, Нидерландов, Польши, Франции и Чехословакии. Кроме того, на Игры прибыли спортсмены из Италии, Румынии и Венгрии. Программа включала соревнования по легкой атлетике, велоспорту, футболу, стрельбе и плаванию.

Чаще всего возникновение видов спорта для лиц с ограниченными возможностями связывают с достижениями английского нейрохирурга

3 Рахматов А. А. Олимпийское движение как средство социализации людей с ограниченными функциональными возможностями // Образование и воспитание. - 2016. - №2. - С. 7.

4 Лысенко И. А. Историко-организационные аспекты развития спорта инвалидов // Педагогика, психология и медико-биологические проблемы физвоспитания и спорта. - 2009. - № 2. - С. 87. 
Л. Гуттмана, который ввел спорт в процесс реабилитации больных с повреждениями спинного мозга. Во время Второй мировой войны на базе Сток-Мандевильского госпиталя Л. Гуттман основал Центр лечения спинных травм. В нем были проведены соревнования по стрельбе из лука для спортсменов на креслах-каталках.

В 1952 году бывшие нидерландские военнослужащие присоединились к движению и основали Международную спортивную федерацию людей с нарушениями опорно-двигательного аппарата. Позднее, в 1956 году Л. Гуттман разработал хартию спортсменов, сформировав основы, на которых в дальнейшем развивался инваспорт.

В 1960 году в Риме по окончании XVII-й Олимпиады были проведены Международные соревнования инвалидов. По сути это были первые Паралимпийские игры, в них приняли участие 400 спортсменов из 23 стран. С 1976 года в соревнованиях стали принимать участие спортсмены других групп: инвалиды по зрению, люди, перенесшие ампутацию конечностей. С каждыми играми возрастало число спортсменов, расширялась география стран-участниц, увеличивалось количество видов спорта. В 1976 году в Швеции состоялись первые зимние Паралимпийские игры (Швеция).

В Республике Беларусь на протяжении длительного периода считалось, что понятия «инвалид» и «физическая активность» / «спорт» сложно совмещаются. Отдельные элементы физической культуры и лечебной физической культуры рекомендовались под строгим контролем врачей как кратковременный комплекс мероприятй, дополняющий физиотерапевтические и медикаментозные назначения.

Однако последние 20-30 лет ситуация меняется. Паралимпийское движение наиболее активно развивается со второй половины 90-х гг. ХХ в., когда Паралимпийский комитет Республики Беларусь был создан и признан международным Паралимпийским комитетом. Физическая культура и спорт, как неотъемлемые элементы здорового образа жизни, прочно входят в жизнь каждого прогрессивного человека, независимо от его возможностей. Белорусские адаптивные спортсмены занимают призовые места на международных соревнованиях, побеждают на олимпиадах.

Отдельной командой Беларусь впервые приняла участие в Паралимпийских играх в 1994 году в Лиллехаммере. С этого года белорусские спортсмены постоянно участвуют в международных состязаниях, выиграв сотни медалей на соревнованиях самого высокого уровня. По различным данным, в Беларуси около 50000 инвалидов занимаются спортом. Наиболее популярны легкая атлетика, плавание, стрельба из лука, биатлон, мини- 
футбол, шахматы, шашки, танцы на инвалидных колясках, велоспорт, лыжные гонки, дзюдо, фехтование.

Тем не менее, многие вопросы правового регулирования адаптивной физической культуры и адаптивного спорта по-прежнему остаются нерешенными. Правовой статус спортсменов-лидеров, тренеров-лидеров, других категорий лиц, участвующих в подготовке и соревнованиях, понятие и свобода адаптивности в спорте, требования к спортивным площадкам и мероприятиям - все это лишь немногие вопросы, требующие детального урегулирования.

Работая в качестве помощника депутата, автор данной статьи принимала активное участие в подготовке законодательства по анализируемой сфере. В комиссиях Парламента Республики Беларусь неоднократно обсуждался законопроект «Об адаптивной физической культуре и адаптивном спорте», учитывающий нормативные правовые акты в рамках $\mathrm{CH}^{5}$, а также опыт зарубежных стран. Тем не менее, пока соответствующее законодательство так и не принято.

Полагаем, в современной Беларуси существует острая необходимость внедрения единого концепта адаптивности, распространяемого на все категории лиц с ограниченными возможностями. В настоящее время физкультурно-спортивное движение среди инвалидов координируют и направляют ОО «Паралимпийский комитет Республики Беларусь», ОО «Белорусская спортивная федерация глухих», ОО «Белорусский комитет Спешиал Олимпикс» и др. К адаптивным спортсменам относятся разнообразные категории лиц с ограниченными возможностями.

По нашему мнению, под мицом с ограниченными возможностями (лицом с ограниченными возможностями функций опорно-двигательного аппарата, зрения, слуха, интеллекта и других функций) следует понимать лицо с физическими, психическими, интеллектуальными или сенсорными особенностями, в том числе: лицо с сахарным диабетом; лицо, перенесшее

5 О новой редакции модельного закона «О физической культуре и спорте»: постановление Межпарламентской Ассамблеи государств - участников Содружества Независимых Государств N 33-23 (принято в г. Санкт-Петербурге 03.12.2009) // Консультант Плюс: Беларусь. Технология 3000 [Электронный ресурс] / ООО «ЮрСпектр». - Минск, 2019; О модельном законе «О паралимпийском спорте»: постановление Межпарламентской Ассамблеи государств-участников Содружества Независимых Государств от 25 ноября 2008 г. N 31-13 // Консультант Плюс: Беларусь. Технология 3000 [Электронный ресурс] / ООО «ЮрСпектр». - Минск, 2019. 
трансплантацию; лицо, перенесшее онкологическое заболевание; лицо, имеющее или имевшее иные стойкие нарушения здоровья, в связи с которыми требуется создание специальных условий для освоения (достижения) результатов в физической и спортивной подготовке, соизмеримых с результатами лиц, не имеющих указанных особенностей.

Адаптивное спортивное движение (адаптивное движение) как форма социального движения имеет целью содействие развитию адаптивной физической культуры и адаптивного спорта, достижению лицами с ограниченными возможностями физического и духовного совершенства, укреплению международного сотрудничества в сфере адаптивной физической культуры и адаптивного спорта. При этом адаптивная фризическая культура - это вид физической культуры, сфера деятельности, представляющая собой совокупность духовных и материальных ценностей, создаваемых и используемых обществом в целях физического развития лиц с ограниченными возможностями, содержащая в себе комплекс эффективных средств реабилитации и абилитации, социальной адаптации и интеграции, укрепления здоровья и способствующая гармоничному развитию личности. Адаптивный cnорт - составная часть спорта, сложившаяся в форме специальной теории и практики подготовки лиц с ограниченными возможностями к спортивным соревнованиям и участия в них с целью физической реабилитации, абилитации, социальной адаптации и интеграции, формирования здорового образа жизни и достижения спортивных результатов на базе создания специальных условий, в том числе условий коммуникации.

Определения физической культуры и спорта сформулированы в Законе Республики Беларусь от 4 января 2014 года N 125-3 «О физической культуре и спорте» (с изм. и доп.) ${ }^{6}$. Согласно абз. 23 п. 1 ст. 1 Закона физическая культура определяется как составная часть культуры, сфера деятельности, представляющая собой совокупность видов деятельности, основанных на духовных и материальных ценностях, создаваемых и используемых обществом в целях физического развития человека, совершенствования его двигательной активности, направленная на укрепление его здоровья и способствующая гармоничному развитию личности. При этом спорт - это

${ }_{6}^{6}$ О физической культуре и спорте: Закон Респ. Беларусь, 4 янв. 2014 г., № 125-3 (в ред. Закона Республики Беларусь от 09.01.2018 N 92-3) // Консультант Плюс: Беларусь. Технология 3000 [Электронный ресурс] / ООО «ЮрСпектр». - Минск, 2019. 
сфера деятельности, представляющая собой совокупность видов спорта, сложившаяся в форме спортивных соревнований и подготовки к ним (абз. 6 п. 1 ст. 1 Закона о спорте). Согласно ст. 45 Конституции Республики Беларусь7, развитием физической культуры и спорта обеспечивается право граждан Республики Беларусь на охрану здоровья.

Адаптивное движение включает следующие направления:

- паралимпийское (пара-направление), развивающее адаптивную физическую культуру и адаптивный спорт среди лиц с нарушениями опорно-двигательного аппарата, другими физическими, в том числе зрительными, особенностями, препятствующими достижению результатов в физической и спортивной подготовке;

- дефлимпийское (деф-направление), развивающее адаптивную физическую культуру и адаптивный спорт среди лиц с особенностями слуха, препятствующими достижению результатов в физической и спортивной подготовке;

- специальное олимпийское (специальное направление), развивающее адаптивную физическую культуру и адаптивный спорт среди лиц с интеллектуальными особенностями, препятствующими достижению результатов в физической и спортивной подготовке;

- другие направления, развивающие адаптивную физическую культуру и адаптивный спорт среди лиц с ограниченными возможностями, в том числе диа-направление среди лиц с сахарным диабетом; трансплантационное направление среди лиц, перенесших трансплантацию органов; онконаправление среди лиц, перенесших онкологическое заболевание и т. д.

Законодательство об адаптивном движении должно регулировать отношения, возникающие при:

- обеспечении прав лиц с ограниченными возможностями на равный доступ к занятиям физической культурой и спортом;

- создании необходимых условий для развития адаптивного движения;

- осуществлении организационной, хозяйственной и иной деятельности в области адаптивного движения;

- организации международного сотрудничества в сфере адаптивного движения;

- разграничении полномочий в области адаптивного движения между

7 Конституция Республики Беларусь 1994 года (с изменениями и дополнениями, принятыми на республиканских референдумах 24 ноября 1996 г. и 17 октября 2004 г.). - Минск : Амалфея, 2005. - 48 с. 
государственными органами, органами местного управления и самоуправления, с одной стороны, и общественными организациями адаптивного движения, с другой стороны.

К ключевым принципам законодательства об адаптивной физической культуре и адаптивном спорте следует отнести:

- гуманистический характер развития адаптивного движения, обеспечение равных условий и возможностей развития адаптивного движения по отношению к условиям и возможностям развития общего спорта и общей физической культуры;

- обеспечение безопасности жизни и здоровья лиц с ограниченными возможностями, участвующих в учебно-тренировочных занятиях, спортивных, физкультурно-спортивных и спортивно-зрелищных мероприятиях;

- доступность физкультурно-спортивных сооружений для занятий, участия в спортивных, физкультурно-спортивных и спортивно-зрелищных мероприятиях, работы и посещения лицами с ограниченными возможностями;

- взаимодействие органов государственной власти в области спорта с общественными спортивными организациями в области адаптивного движения с обязательным привлечением последних к разработке и принятию решений, затрагивающих интересы адаптивного движения, в том числе при проектировании, строительстве и реконструкции спортивных и иных объектов, необходимых для подготовки спортсменов и проведения мероприятий;

- приоритет норм международного права в области адаптивного движения.

Ключевой категорией правового регулирования адаптивного движения следует признать свободу адаптивности. Она означает, что лицо с ограниченными возможностями имеет право на занятие адаптивной физической культурой и доступными видами адаптивного спорта по направлению, соответствующему его особенностям, а также на занятие физической культурой и спортом с лицами без нарушений. Каждое лицо с ограниченными возможностями вправе самостоятельно решать, каким образом - в рамках общей физической культуры (спорта) либо адаптивной физической культуры (спорта) - осуществлять занятия, на каких условиях участвовать в соревнованиях и других мероприятиях.

Это положение особенно важно с учетом того факта, что премии и вознаграждение адаптивных спортсменов пока еще в разы меньше 
аналогичных премий и вознаграждений обычных спортсменов. При этом, некоторые из адаптивных спортсменов (например, дефлимпийцы) выражают готовность принимать участие в соревнованиях наравне с обычными спортсменами.

Частью свободы адаптивности можно признать право лиц с ограниченными возможностями на свободное осуществление любой профессиональной деятельности в сфере физической культуры и спорта, в том числе в качестве спортсмена, тренера и т. д., а также в других сферах. Строительство физкультурно-спортивных сооружений и проведение мероприятий должны проводиться с учетом потребностей лиц с ограниченными возможностями, их права на доступ в такие сооружения (на мероприятия), правом на участие в тренировочном и спортивном процессе в любом качестве. Следует предусмотреть запрет на проектирование, разработку проектных решений, строительство и реконструкцию физкультурно-спортивных сооружений без их приспособления для свободного доступа и использования лицами с ограниченными возможностями. При этом необходимо учитывать, что свободный доступ в соответствующие зоны физкультурно-спортивных сооружений и использование этих зон должны быть обеспечены любым лицам с ограниченными возможностями: спортсменам, тренерам, спортивным врачам, массажистам, судьям, классификаторам, инструкторам, болельщикам и другим. Также должен быть обеспечен свободный доступ к физкультурноспортивным сооружениям лицам с визуальными нарушениями с собакамипроводниками.

В законодательстве об адаптивном движении должны быть определены общие и частные меры меры государственной поддержки адаптивного движения с учетом его специфики, социальные гарантии и формы финансового обеспечения в этой области, а также - организационноправовые основы адаптивного движения с учетом его особенностей. Необходимо детальное регулирование таких основополагающих в области адаптивного спорта аспектов, как спортивно-медицинская классификация спортсменов по степени их функциональных возможностей; календарный план спортивных мероприятий; правила соревнований; учебнотренировочные программы по адаптивным видам спорта и другие.

Важнейшим аспектом поддержки адаптивного движения является регулирование деятельности детско-юношеских спортивных школ и иных спортивных учреждений, участвующих в адаптивном движении, закрепление конкретных мер государственной поддержки в данной сфере, систематизация 
нормативных правовых норм. В настоящее время работа спортивных организаций инвалидов, центральных и территориальных органов исполнительной власти, ведомственных структур в области физической культуры и спорта зачастую сводится лишь к проведению соревнований по паралимпийским видам спорта и обеспечению участия сильнейших спортсменов в национальных и международных турнирах. При этом мало внимания уделяется комплексной, целенаправленной деятельности по созданию условий и предпосылок для выявления и подготовки таких спортсменов, агитации адаптивного движения, стимулированию лиц с ограниченными возможностями к участию в адаптивном движении, созданию условий для развития физической культуры всех категорий лиц с ограниченными возможностями.

В действующем белорусском законодательстве четко не определен статус «спортсмена-лидера» (пилот, партнёр) и «тренера-лидера», что создает серьезные сложности для участия этих лиц в тренировочном процессе и соревнованиях. В соответствии с международными правилами соревнований по отдельным видам спорта в определенных паралимпииских дисциплинах наряду со спортсменом с ограниченными возможностями обязательно участие «лидеров» (лыжные гонки, биатлон, легкая атлетика), «пилотов» (велоспорт), «партнеров» (танцы на инвалидных колясках). Эта категория в статусе спортсменов входит в списочные составы национальной и сборных команд Республики Беларусь по инваспорту, которые ежегодно утверждаются Министром спорта и туризма Республики Беларусь по результатам аттестации. Однако в связи с отсутствием указанных профессий в общегосударственном классификаторе Республики Беларусь (ОКРБ 006-2009) лидеры, пилоты, партнеры, завоевавшие в тандеме со спортсменами с ограниченными возможностями призовые места на международных соревнованиях и награжденные медалями того же достоинства, не могут претендовать на вознаграждение за показанный результат. Это порождает серьезные проблемы, в том числе в процессе привлечения молодых спортсменов к занятиям и участию в спортивных мероприятиях.

Таким образом, в настоящее время существует острая необходимость в принятии в Республике Беларусь специального законодательства, комплексно и единообразно регулирующего и поддерживающего адаптивное движение. Ведутся споры относительно того, должен это быть отдельный Закон Республики Беларусь «Об адаптивной физической культуре и адаптивном 
спорте» или глава в общем Спортивном кодексе Республики Беларусь ${ }^{8}$. Полагаем, что данный вопрос вряд ли можно отнести к числу принципиальных. При этом совершенно очевидно, что разрешение существующих противоречий и устранение коллизий разрозненных нормативных правовых актов крайне актуальны и важны для дальнейшего развития адаптивного движения.

Dr. habil. Julia Gavrilchenko (Minsk, Belarus)

Improving the legal regulation of adaptive sports movement in the Republic of Belarus The article examines the issues of the emergence and development of adaptive medical and rehabilitation movement, medical and legal regulation of adaptive physical education and adaptive sports. Based on the analysis of the current legislation and law enforcement practice, the author comes to the conclusion that modern Belarusian law needs the adoption of a normative legal act regulating and supporting the adaptive movement in the Republic of Belarus. The article formulates the basic definitions of adaptive physical education and sports (a person with disabilities, adaptive movement, adaptive physical education, adaptive sports, etc.), key principles of legislation in this area. The author explores the concept of freedom of adaptability and, as a result, formulates concrete proposals for filling in the gaps and eliminating conflicts in the legal regulation of adaptive movement.

Keywords: Belarusian Legislation, Medical Law, a Person with Disabilities, Disability, Adaptive Movement, Physical Education, Freedom of Adaptability.

профессор Юлия Гаврильченко (Минск, Беларусь)

\section{Совершенствование правового регулирования адаптивного спортивного движения в Республике Беларусь}

В статье исследуются вопросы возникновения и развития адаптивного медикореабилитационного движения, медико-правового регулирования адаптивной физической культуры и адаптивного спорта. На основе анализа действующего законодательства и правореализационной практики автор приходит к выводу о том, что современное белорусское право нуждается в принятии нормативного правового акта, регулирующего и поддерживающего адаптивное движение в Республике Беларусь. В статье формулируются основные определения адаптивных физической культуры и спорта (лицо с ограниченными возможностями, адаптивное движение, адаптивная физическая культура, адаптивный спорт, др.), ключевые принципы законодательства в данной сфере. Автор исследует концепт «свобода адаптивности» и в результате формулирует конкретные предложения по восполнению пробелов и

${ }^{8}$ Корочкин А. Ю. Нужен ли в Беларуси Спортивный кодекс // Консультант Плюс: Беларусь. Технология 3000 [Электронный ресурс] / ООО «ЮрСпектр». - Минск, 2019. 